\title{
LA VIOLENCIA DE GÉNERO EN LOS ORDENAMIENTOS JURÍDICOS DE INSPIRACIÓN LATINA: \\ (II) GLOBALIZACIÓN Y DISCRIMINACIÓN CONTRA LA MUJER
}

\section{GENDER VIOLENCE IN THE LEGAL SYSTEMS OF CIVIL LAW: (II) GLOBALIZATION AND DISCRIMINATION AGAINST THE WOMAN}

\author{
Juana María González Moreno ${ }^{1}$
}

\section{RESUMEN}

Este trabajo representa la continuación de nuestro estudio titulado "La violencia de género en los ordenamientos jurídicos de inspiración latina (I) América Latina versus Europa: discriminaciones de ida y vuelta", presentado en la Quinta Conferencia Europea sobre Investigación Feminista, "Gender and Power in the New Europe" (Lund, Suecia, agosto de 2003), y en el que tratamos de ilustrar, a través del análisis del ordenamiento jurídico peruano, cómo la violencia contra la mujer contenida en los ordenamientos jurídicos latinoamericanos es mayor que la violencia que producen los ordenamientos jurídicos de países europeos. En esta segunda parte, ponemos de manifiesto cómo la globalización ha supuesto un reforzamiento de la violencia de género contenida en los distintos ordenamientos jurídicos.

Palabras clave: Discriminación, derecho, género, globalización, Latinoamérica, violencia, mujeres.

\section{ABSTRACT}

These work represents the continuation of our titled study "The gender violence in the legal systems of Civil Law (I) Latin America versus Europe: discriminations of coming and going", presented in the Fifth European Conference on Feminist Investigation, "Gender and Power in New the Europe" (Lund, Sweden, August of 2003), and in which we try to illustrate, through the analysis of the Peruvian legal system, how the violence against the woman contained in the Latin American legal systems is bigger than the violence that the legal systems of European countries produces. In this second part, we show how the globalization has supposed a reinforcement of the contained in the different legal systems gender violence.

Key words: Discrimination, law, gender, globalization, Latinmerican, violence, women.

\section{INTRODUCCIÓN}

Punto de partida: (I) América Latina versus Europa: discriminaciones de ida y vuelta".

El trabajo contiene parte de los resultados alcanzados en el desarrollo del proyecto denominado La violencia de género en los ordenamientos jurídicos de inspiración latina (2003 2004). Un primer bloque de resultados fue objeto de comunicación en la Quinta Conferencia Europea sobre Investigación Feminista, "Gender and Power in the New Europe" (Lund, Suecia, agosto de 2003) (1), bajo el título (I) América Latina versus Europa: discriminaciones de ida y vuelta".

Entre los aspectos que entonces se pusieron de manifiesto, cabe destacar, básicamente, dos: un aspecto, ya constatado por la doctrina feminista, es que el Derecho constituye en sí mismo un instrumento generador de violencia contra las mujeres, al con- sagrar en sus propias normas jurídicas, así como en su interpretación y aplicación por los Jueces y Tribunales, los papeles estereotipados de hombres y mujeres asentados en nuestra cultura, que son los que propician la violencia contra las mujeres; y un segundo aspecto está representado por el hecho de que la violencia que produce el Derecho contra las mujeres es mayor en los ordenamientos jurídicos de los países que, por motivos históricos, estuvieron bajo la dominación política, social, económica, cultural, y también jurídica de los países europeos (en particular, de España), debido al influjo que sobre ellos ha tenido el modelo latino de ordenamiento jurídico, de inspiración romana y a la visión subordinada de la mujer contenida en el mismo, tal como se ha constatado a lo largo de nuestro análisis del ordenamiento jurídico peruano.

Objetivo de (II): Europa vs. América Latina: globalización y discrimina- ción contra la mujer.

En esta segunda parte de La violencia de género en los ordenamientos jurídicos de inspiración latina, tratamos de analizar la incidencia de los procesos de globalización sobre los ordenamientos jurídicos, especialmente sobre los ordenamientos jurídicos español y peruano, y las consecuencias de estas influencias en la condición jurídica de las mujeres.

Motivaciones de (I) y (II).

La motivación que nos ha animado a lo largo de nuestro trabajo, tanto en la primera como en la segunda parte, ha sido, una preocupación general por la violencia de género producida por el propio Derecho, violencia que constituye un obstáculo a la igualdad real entre hombres y mujeres. A ello hay que añadir nuestro afán por desvelar los factores que han determinado el ser del ordenamiento jurídico peruano, y en específico, el tratamiento que

${ }^{1}$ Universidad de Granada, España 
dispensa a las mujeres, así como la necesidad de visualizar la responsabilidad de Europa (en concreto, del ordenamiento jurídico español), en la gestación y reproducción de la violencia contra las mujeres que contiene el ordenamiento jurídico peruano.

\section{Peculiaridad de nuestra aportación} en (I) y (II).

Creemos que la peculiaridad de nuestra aportación en el análisis de la violencia de género en los ordenamientos jurídicos de inspiración latina reside en el carácter plural del enfoque que adoptamos ya que, al mismo tiempo que tratamos de hacer un análisis de Derecho comparado, vinculando los ordenamientos jurídicos español y peruano en su presente y en su pasado, nos situamos en la teoría jurídica feminista, y tratamos de aplicar el esquema de análisis del Derecho propuesto por Carol Smart, que implica transitar por tres estadios que simbolizan, respectivamente, las frases: "el Derecho es sexista", "el Derecho es masculino", y "el Derecho tiene género" $(2,3)$.

\section{Aporte concreto de (II).}

Por lo que se refiere a la segunda parte del trabajo, nuestro aporte ha consistido en evidenciar cómo el fenómeno de la globalización ha contribuido a la reproducción y fortalecimiento de las desigualdades heredadas del pasado. Fundamentalmente, porque el impacto de la globalización sobre el Derecho - que es uno de los aspectos descuidado en los análisis de la globalización-, ha significado, en los ordenamientos jurídicos latinoamericanos, la radicalización de dos procesos, que son la occidentalización y el formalismo, los cuales no conducen a una protección efectiva de los derechos de las mujeres.

\section{Limitaciones.}

No estudiamos todos los ordenamientos jurídicos inspirados en el Civil Law sino que hemos acotado nuestro objeto a los ordenamientos jurídicos español y peruano. Tampoco respecto de cada uno de los ordenamientos jurídicos seleccionados y respecto a los procesos globalizadores, hemos pretendido un análisis cuantitativo ni tampoco exhaustivo. Básicamente, manejamos una serie de datos desde un punto de vista cualitativo, con el fin de servir de pretexto o motivación para futuras investigaciones.

\section{RESULTADOS.}

La prevalencia de la dimensión económica de la globalización.

El examen de la literatura acerca de la globalización pone de manifiesto que la globalización es considerada, ante todo, como un fenómeno de carácter económico, fenómeno que además, es presentado como inevitable (se naturaliza la globalización económica).

Sin embargo, este reduccionismo economicista desde el que se contempla la globalización, provoca la confusión conceptual de la especie (globalización económica), con el género (globalización, a secas), y el que pasen desapercibidas las demás dimensiones de la globalización, por la que hay que entender, en sentido general, "el actuar y vivir superando todo tipo de separaciones (en los mundos aparentemente separados de los Estados nacionales, las religiones, las regiones y los continentes)" (4), o el proceso de comprensión y toma de conciencia del mundo como globalidad (5).

La inexistencia de una vivencia, comprensión y conciencia del Derecho como globalidad.

En el ámbito jurídico, no puede decirse que el Derecho sea vivido, comprendido y objeto de una toma en conciencia como globalidad, que son las notas que implica el concepto de globalización, según BECK e HSIAO. El Derecho no sale aún de los márgenes estatales, a diferencia de lo que ocurre con la economía que ha escapado al control de prácticamente todos los Estados (4), y más bien lo que se registran son distintos efectos en el Derecho como consecuencia de la incidencia en el mismo de la globalización económica o globalismo.

La instrumentalización del Derecho al servicio de la globalización económica.

El principal efecto que provoca la globalización económica es la compulsión a los Estados a "fabricar" un Derecho a la medida de aquélla. Un Derecho que, por otra parte, es comprendido conforme al mismo paradigma positivista imperante desde hace siglos: el paradigma positivista, cientificista, dogmático, que se ha exportado al ámbito jurídico, conforme al cual, el Derecho es concebido como un instrumento lógico, racional, neutral y objetivo, que permite alcanzar la justicia con su sola aplicación a la realidad.

Tal modo de comprensión del Derecho, que es el que ha predominado en los países que adoptaron el modelo latino de ordenamiento jurídico (Civil Law), ha sido radicalizado por la globalización económica, pues es el que mejor sirve a los intereses de una Economía que también es presentada como espacio neutral, objetivo, sin color... (aunque estos adjetivos no tengan correspondencia con la realidad).

No obstante, la incidencia de la globalización económica sobre el Derecho, en países latinoamericanos como Perú, es mayor y más negativa que la que se verifica en los contextos español o europeo, debido, sobre todo, a sus diferentes condiciones (históricas, sociales, políticas, económicas) de partida. Estas condiciones han determinado, entre otras cosas, el predominio, aún con más fuerza que en España, del paradigma positivista de comprensión del Derecho. De un Derecho que, por otra parte, ha estado y sigue estando muy distante de la realidad, y que ha devenido cada vez más formalista.

La incidencia de la globalización económica sobre el Derecho incrementa la violencia contra las mujeres.

La incidencia de la globalización, en su dimensión económica, sobre el Derecho provoca mayor violencia hacia las mujeres al fortalecer el paradigma positivista de comprensión del Derecho, y disminuir las posibilidades de cuestionamiento de dicho paradigma, el cual invisibiliza la violencia contra la mujer, e incrementa el riesgo de radicalización de sesgos masculinos y modelos normativos en las normas jurídicas y en la jurisprudencia, como ha ocurrido en España.

En Perú, la desigualdad y discriminación contra la mujer, que aún están presentes en su ordenamiento jurídico en sus diversas formas (discriminaciones sexistas, sesgos masculinos, modelos normativos), se ven duplicadas por el impacto de la globalización económica sobre el Derecho. Además, el fortalecimiento del paradigma positivista de comprensión del Derecho, da lugar a matices diferenciales, como son: un mayor forma- 
lismo jurídico; un elevado grado de incumplimiento de las normas jurídicas; una tendencia a la producción de normas en relación con las problemáticas que afectan a las mujeres, aunque tengan un efecto meramente simbólico o se atente contra los principios básicos que deben inspirar a todo Estado que se precie de ser democrático y social de Derecho; una mayor abstracción del orden jurídico; una radicalización del dogmatismo y del acriticismo hacia el Derecho existente y hacia el Derecho importado, lo que incrementa a su vez la occidentalización del ordenamiento jurídico peruano, y con ello, la persistencia de la concepción subordinada de la mujer, que aún alimenta sus normas, su doctrina y su jurisprudencia.

\section{CONCLUSIÓN}

La globalización, fundamentalmente en su dimensión económica, que es la que más ha impactado en el Derecho, amplifica las discriminaciones contra las mujeres que aún contienen los ordenamientos jurídicos, y la aceptación acrítica de las mismas.

Sin embargo, ello no debe llevar a renunciar al Derecho como mecanismo para conseguir justicia para las mujeres, sino a ser conscientes de sus limitaciones y de la necesidad de un uso diferente del mismo. Un uso que, por otra parte, no debe ser un uso esencialista, de defensa a ultranza de las mujeres. Tampoco la puesta en marcha de "otra globalización" como reclaman distintos movimientos, entre ellos los partidarios de un feminismo global -, debe ser esencialista. Hay que trabajar para hacer más reales y efectivos los derechos de las mujeres, pero sin caer en esencialismos, y en un victimismo pernicioso.

\section{AGRADECIMIENTOS.}

La realización de este trabajo se enmarca en el proyecto de investigación La violencia de género en los ordenamientos jurídicos de inspiración latina, 2003 - 2004, financiado por el Ministerio de Asuntos Exteriores de España - Agencia Española de Cooperación Internacional (AECI). A las autoridades de la Universidad Nacional de Trujillo, Perú, la acogida en su Universidad, en la que hemos hecho parte de la investigación, a los organizadores de este Encuentro Científico Internacional, la aceptación de nuestro trabajo, a pesar de que nuestro ámbito de estudio es el Derecho, cuyo carácter de Ciencia ha estado en cuestión, y de que nuestro posicionamiento en la teoría jurídica feminista

nos lleva a criticar el paradigma de ciencia imperante, el paradigma positivista, cientificista.

\section{REFERENCIAS BIBLIOGRÁFICAS}

1. González Moreno JM. Gender violence in the legal systems of Civil Law (I) Latin América vs. Europa: discriminations of coming and going. [paper] Fith European Conference of Feminist Research, "Gender and Power in the New Europe" (Lund, Sweden, Aug 2003), http://www.5thfeminist.lu.se/ filer/paper 502.pdf).

2. Smart C. La mujer del discurso jurídico. En: Mujeres, Derecho penal y criminología. Madrid: Siglo XXI Editores, S.A.; 1994, pp.168 -189.

3. Smart, C. La teoría feminista y el discurso jurídico. En: El Derecho en el Género y el Género en el Derecho. Buenos Aires: Ceadel, Ed. Biblos; 2000. pp. $31-71$.

4. Beck, U. ¿Qué es la globalización? Falacias del globalismo, respuestas a la globalización. Barcelona: Paidós, Colección Estado y Sociedad; 1998.

5. Hsiao, H.-H. M. Coexistencia y síntesis. Globalización y localización cultural en el Taiwán contemporáneo. En: Globalizaciones múltiples. La diversidad cultural en el mundo contemporáneo, Barcelona: Paidós, Colección Estado y Sociedad; 2002. pp. $65-85$.

Email: juanamariagonzalez@yahoo.es 